\title{
Comprehensive sector-wide strategies to prevent and control obesity: what are the potential health and broader societal benefits? A case study from Australia
}

\section{James Kite ${ }^{a}$, Debra Hector ${ }^{a}$, Alexis St George ${ }^{a}$, Zeljko Pedisic ${ }^{a, b, c}$, Philayrath Phongsavana, Adrian Baumanª, Jo Mitchelld and Bill Bellewa,e}

a School of Public Health, University of Sydney, NSW, Australia

${ }^{b}$ Faculty of Kinesiology, University of Zagreb, Croatia

c Institute of Sport, Exercise and Active Living, Victoria University, Melbourne, Australia

${ }^{d}$ NSW Ministry of Health, Sydney, Australia

e Corresponding author: william.bellew@sydney.edu.au

\section{Article history}

Publication date: September 2015 Citation: Kite J, Hector D, St George A, Pedisic Z, Phongsavan P, Bauman A, Mitchell J, Bellew B. Comprehensive sectorwide strategies to prevent and control obesity: what are the potential health and broader societal benefits? A case study from Australia. Public Health Res Pract. 2015;25(4):e2541545. doi: http://dx.doi. org/10.17061/phrp2541545

\section{Key points}

- Several countries have established comprehensive strategies to prevent or control overweight and obesity

- Studies have not yet been conducted on the effectiveness and impact of these strategies on obesity prevalence

- A case study in New South Wales shows that health and societal benefits from successful implementation are likely to be substantial if specified targets are achieved

- Evaluation of multisectoral strategies is a key priority for obesity prevention efforts

\section{Abstract}

Aim: Several countries have recently established multistakeholder strategies to prevent or control overweight and obesity; however, studies have not yet been done on their effectiveness and likely impact. This study's objectives were to (i) explore sector-wide benefits and impacts likely to accrue from implementing an obesity prevention strategy in the Australian state of New South Wales; (ii) discuss the wider implications of the findings for research and practice; and (iii) strengthen the case for sustained implementation of a comprehensive, intersectoral approach.

Method: A case study approach, including evidence reviews and illustrative epidemiological models, was used to show potential benefits from meeting selected targets and objectives specified in the strategy.

Results: For adults, improved health outcomes potentially include reductions in all-cause mortality, cardiovascular disease, type 2 diabetes, various cancers, osteoarthritis, infant mortality and healthcare costs. Potential benefits beyond the health sector involve disability payments, absenteeism, worker productivity, workplace injuries and insurance claims. For children and adolescents, improved health outcomes potentially include metabolic risk factors, dental health, prehypertension/hypertension, cardiovascular disease risk factors, depression, rates of mortality in hospitalised children, bullying and otitis media.

Conclusion: Sector-wide health, social and economic benefits from successful implementation of multisector obesity prevention strategies are likely to be substantial if specified targets are achieved. Epidemiological modelling described in this paper for selected examples provides illustrative rather than comprehensive evidence for potential benefits. Process evaluation 
of the extent of implementation of these multisectoral strategies, together with the accumulated data on intervention effectiveness, will determine their potential population health benefit. Quantifying the health and social benefits that are likely to accrue if comprehensive sector-wide obesity prevention and control strategies are established can strengthen advocacy for their sustained implementation.

\section{Introduction}

The prevalence of overweight and obesity is rising internationally. ${ }^{1}$ Most of the adult population, and one in five children, are now overweight or obese in Organisation for Economic Co-operation and Development (OECD) countries. ${ }^{2}$ Although weight gains were largely beneficial to the health and longevity of our ancestors, substantial proportions of the populations in these countries have now crossed the line beyond which further gains compromise health. ${ }^{2}$ As body mass index increases, so too does the prevalence of comorbid conditions, including diabetes, cardiovascular disease and some cancers. ${ }^{3}$ Severely obese people die 8-10 years sooner than people of healthy weight, with every 15 extra kilograms increasing the risk of early death by approximately $30 \% .^{2}$ Rising medical costs are associated with increasing prevalence of both overweight and obesity. ${ }^{4}$ Obesity is estimated to be responsible for $1-3 \%$ of total health expenditure in most developed countries (and $5-10 \%$ in the US), with costs expected to rise rapidly in coming years as obesity-related diseases become more prevalent. ${ }^{2,4}$

As recently noted by the OECD ${ }^{2}$ and the World Health

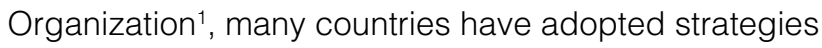
and policies to prevent or control overweight and obesity. Best practice includes multistakeholder frameworks, which involve business and civil society actors in the development of public health policies ${ }^{5}$; however, because these frameworks have only recently been implemented, evidence of their effectiveness and likely impact is just beginning to emerge. ${ }^{1,2}$ This paper takes a case study approach to examining a multistakeholder obesity prevention strategy in the Australian state of New South Wales (NSW) - the NSW Healthy Eating Active Living (HEAL) Strategy 2013-2018 (www.health.nsw.gov.au/ heal). Specifically, we used epidemiological modelling to demonstrate potential benefits from meeting a subset of the targets specified in the HEAL Strategy.

The HEAL Strategy provides a whole-of-government framework to promote and support healthy eating and active living in NSW, and reduce the impact of lifestylerelated chronic disease. The strategy sets a number of targets that aim to encourage and support the community to make healthy lifestyle changes at a personal level, and create an environment that supports healthier living, through better planning, built environments and transport solutions (Box 1). To achieve these targets, the strategy includes activities such as state-wide and targeted programs for children and young people, workplacebased programs to support physical activity and healthy eating, changes to urban planning and design processes to encourage and facilitate active living and healthy eating, expansion of the telephone-based Get Healthy Information and Coaching Service, targeted programs for people with prediabetes and women at risk of gestational diabetes to prevent progression to type 2 diabetes, and changes to consumer nutrition information requirements and communication.

Box 1. Targets and objectives of the NSW Healthy Eating Active Living Strategy 2013-2018

\section{Targets}

- Reduce overweight and obesity rates of children and young people (5-16 years) to $21 \%$ by 2015

- Stabilise overweight and obesity rates in adults by 2015 , and then reduce them by $5 \%$ by 2020

- Increase participation in sport, recreational, arts and cultural activities in rural and regional NSW by $10 \%$ and in Sydney by $10 \%$ from 2010 to 2016

- More than double the mode share of bicycle trips made in the Greater Sydney region at local and district levels by 2016

- Increase the mode share of walking trips made in the Greater Sydney region at local and district levels to $25 \%$ by 2016

- Increase the proportion of total journeys to work by public transport in the Sydney Metropolitan Region to $28 \%$ by 2016

- Increase the percentage of the population living within 30 minutes by public transport of a city or major centre in metropolitan Sydney

\section{Objectives}

1. Reduce intake of energy-dense, nutrient-poor food and drinks

2. Increase consumption of fruit and vegetables

3. Increase incidental, moderate and vigorous physical activity

4. Reduce time spent in sedentary behaviours

5. Increase community awareness of healthy eating and physical activity as protective factors against chronic disease

6. Increase intake of water in preference to sugarsweetened drinks 


\section{Methods}

Evidence reviews and epidemiological models were used to illustrate examples of sector-wide benefits that could accrue as a consequence of successful HEAL Strategy implementation (i.e. meeting specified targets and objectives).

\section{Evidence reviews}

A rapid evidence review was undertaken between August and October 2014. The review's scope was confined to the overweight and obesity targets for adults and children, and the six strategic objectives (see Box 1). Box 1 shows the HEAL Strategy targets and objectives as set out in the strategy document itself; this analysis focused on quantifiable targets (overweight and obesity) and directional targets (as shown in Table 1). The review scope did not include the targets on participation in sport, recreational, arts and cultural activities, and active travel.

This review followed the Evidence Check methodology (www.saxinstitute.org.au/our-work/knowledge-exchange/ evidence-check), which does not comprehensively review all the literature relating to the topic area, but reviews evidence tailored to policy maker needs in a policyfriendly format. Reviewers identify gaps in the evidence but do not undertake new research to fill these gaps. The review's purpose was to:

- Identify additional health conditions and wellbeing indicators (beyond overweight and obesity) where there is strong evidence that meeting the HEAL Strategy's specified targets will improve outcomes

- Provide information on the level of change in the targets that are associated with better outcomes for illustrative health conditions and wellbeing indicators

- Examine in greater detail the use of this method in the context of global obesity prevention

- Discuss the implications of the review findings for research and practice.

\section{Search strategy}

Searches were undertaken to identify articles about specific health conditions and other (direct or indirect) outcomes associated with:

- Reducing overweight and obesity

- Reduced consumption of energy-dense, nutrientpoor foods

- Increased fruit and vegetable consumption

- Increased water consumption and reduced consumption of sugar-sweetened drinks

- Increased incidental and moderate-to-vigorous physical activity

- Reduced sedentary behaviours

- Improved community awareness of healthy eating and physical activity as protective factors against chronic disease.
Searches were undertaken to identify articles reporting on epidemiological associations with any of the following direct health outcomes:

- Cardiovascular disease

- Cancer

- Hypertension

- Anxiety or depression

- Arthritis

- Type 2 diabetes

- Morbidity associated with the above conditions

- Mortality

- Wellbeing indicators.

Wellbeing was broadly defined and included dimensions such as school or social participation, childhood development, injurious falls and healthrelated quality of life. The searches also aimed to identify associations with other direct or indirect outcomes (e.g. performance at school or economic benefits). The searches were restricted to studies published between January 2000 and September 2014, except for the exposure variables of overweight and obesity, for which the search was restricted to 2012-2014. Evidence from meta-analytic and systematic reviews on individual health outcomes was included from 2012 onwards because of the vast amount of literature on the association between overweight and obesity and health outcomes. In all cases, the most recently published meta-analysis or review article for each outcome was used. Searches of Medline, Pre-Medline and PsychINFO were undertaken using Medical Subject Headings (MeSH) terms and keywords (phrase searching) to identify recent reviews, systematic reviews and meta-analyses of population studies.

Search strategies were tailored for each target and objective; the most recent data from the highest quality studies were extracted, wherever possible. Articles were screened on the basis of title and abstract, and, where required, full articles were obtained. Only articles that reported on the association using appropriate statistical methods were included. Narrative reviews were excluded. Articles with nonsignificant findings were generally not selected, except for the effects of overweight and obesity in children, for which few risk measures were reported in the literature. A limited grey literature search was also conducted. Details of the search strategies can be accessed in supplementary online material: ses.library. usyd.edu.au/handle/2123/8718

\section{Epidemiological models}

Population attributable risk (PAR)-based estimation of lives saved and diseases prevented through implementation of the HEAL Strategy was undertaken for five illustrative examples of the potential outcomes of strategy effectiveness: (i) physical activity and colorectal cancer, (ii) fruit and vegetable consumption and coronary heart disease, (iii) sugar-sweetened beverage consumption and type 2 diabetes, (iv) sedentary behaviour (sitting time) and all-cause mortality, and 
(v) overweight and obesity and type 2 diabetes. The outcomes were selected based on the burden of disease in Australia, as identified by Begg et al. ${ }^{6}$ Epidemiological modelling was used to examine the effect of achieving targets and objectives for selected health outcomes. PARs were calculated to quantify the benefit that could be expected for selected health outcomes if the HEAL Strategy targets and objectives were met.

PARs estimate the proportion of events (cases, deaths, hospitalisations, etc.) that can be attributed to a particular risk factor - for example, the proportion of lung cancer cases attributable to smoking. PARs were calculated as:

$$
P A R=\frac{P_{e}\left(R R_{e}-1\right)}{R R_{e}}
$$

where $P_{e}$ is the prevalence of the risk factor in the population and $R R_{e}$ is the relative risk (RR) of the event, adjusted for confounding factors.

RRs were sourced from the most recent meta-analyses identified as part of the evidence review; earlier metaanalyses were examined to ensure consistency of the RR selected. Prevalence of insufficient physical activity (less than 150 minutes/week), insufficient fruit consumption (less than two serves/day) and vegetable consumption (less than five serves/day), and overweight and obesity were sourced from the NSW Population Health Survey. ${ }^{7}$ Sugar-sweetened beverage consumption was sourced from the Australian Health Survey ${ }^{8}$, and sitting time prevalence was calculated using national data from the recent 20-country study. ${ }^{9}$ All data were for adults. After calculating the PAR for each risk factor and associated outcome, we determined the number of events that would be avoided if the HEAL Strategy targets and objectives were met, using the formula from Lee et al. (2012) ${ }^{10}$ :

\section{Avoided events $=I_{e} \times P A R \times \triangle$}

where $I_{e}$ is the incidence of the outcome in the NSW population and $\Delta$ is the targeted change in the risk factor. The targeted change in adult overweight and obesity (a $5 \%$ reduction by 2020) was based on the HEAL Strategy target. For physical activity and healthy eating, the modelled targets were consistent with the outcomes and performance benchmarks stipulated in the National Partnership Agreement on Preventive Health (www. federalfinancialrelations.gov.au/content/npa/health_ preventive/national_partnership.pdf). For sedentary behaviour and sugar-sweetened beverage consumption, the modelled targets were consistent with the magnitude of change reported in recent systematic reviews. ${ }^{11,12}$

A better PAR method would have considered $P_{d}$, the prevalence of exposure in those with the outcome of interest; however, the health surveys used could only be used to calculate $P_{e}$. This provides conservative estimates of the cases avoided, because, whenever a risk factor is positively associated with an outcome (as in all our examples), $P_{e}$ is lower than $P_{d}$. This means that all our estimates are lower than they would be if we used the technically more correct $P_{d}$.

\section{Results}

\section{Quality of evidence}

For multiple health and other outcomes in relation to achieving the HEAL Strategy targets for overweight and obesity, few articles were identified in the peer-reviewed literature. Evidence from meta-analytic and systematic reviews on individual health outcomes was identified from 2012 onwards. For increased fruit and vegetable consumption, 12 systematic reviews were available. With respect to sugar-sweetened beverages, three systematic reviews and meta-analyses of prospective cohorts were used, along with six single-cohort studies. For increased physical activity, 15 systematic reviews of prospective cohorts, and a further 10 with a combination of cohort and case-control studies were used. For reduced sedentary behaviour, four systematic reviews of prospective cohorts and a further three with a combination of cohort and case-control studies were used. For reduced consumption of energy-dense, nutrient-poor food, no systematic reviews or meta-analyses of population studies were identified; evidence on associations of these foods with major health outcomes from single population studies (cohort and case-control studies) was used.

\section{Improved outcomes from effective strategy implementation}

For adults, examples of improved health outcomes from meeting the HEAL Strategy targets and objectives include all-cause mortality, cardiovascular disease, type 2 diabetes, various cancers, osteoarthritis, infant mortality and healthcare costs. $3,4,13-28$ Benefit areas beyond the health sector include disability payments, workplace absenteeism and productivity, workplace injuries and insurance claims. ${ }^{29-32}$ For children and adolescents, improved health outcomes from meeting the HEAL Strategy targets and objectives include metabolic risk factors, dental health, prehypertension/hypertension, cardiovascular disease risk factors, improved mental health and reduced depression, mortality rates in hospitalised children, bullying, and otitis media. ${ }^{33-38}$

\section{Estimates of the potential lives saved and diseases prevented}

Data models were premised on hypothetically achievable targets - namely, 5\% reduction in obesity, $5 \%$ reduction in overweight, $15 \%$ relative reduction in insufficient physical activity, $25 \%$ relative reduction in sedentary behaviour, $25 \%$ relative reduction in sugar-sweetened beverage consumption, $25 \%$ reduction in insufficient fruit consumption and $10 \%$ reduction in insufficient vegetable 
consumption. These data models suggest that, every year in NSW, meeting the targets and objectives could prevent at least 37 colorectal cancer cases (through increased physical activity) and at least 366 deaths from all causes (through reduced sedentary behaviour). For coronary heart disease, 351 cases could be prevented through increased vegetable consumption, and 370 cases could be prevented through increased fruit consumption. For type 2 diabetes, meeting the targets and objectives could prevent 510 cases through reduced sugar-sweetened beverage consumption, 466 cases through reduced prevalence of overweight, and 371 cases through reduced prevalence of obesity. The details of these examples are shown in Table 1.

Table 1. Estimated lives saved and diseases prevented every year in NSW by meeting targets in selected scenarios

\begin{tabular}{|c|c|c|c|c|c|c|c|c|}
\hline $\begin{array}{l}\text { Exposure } \\
\text { variable }\end{array}$ & $\begin{array}{l}\text { Outcome } \\
\text { measure }\end{array}$ & $\begin{array}{c}\text { Target } \\
\text { reduction } \\
\text { in } \\
\text { exposure } \\
\text { variable } \\
\text { prevalence }\end{array}$ & $\begin{array}{c}\text { Current } \\
\text { exposure } \\
\text { variable } \\
\text { prevalence }\end{array}$ & $\begin{array}{c}\text { Relative risk of } \\
\text { outcome measure }\end{array}$ & $\begin{array}{l}\text { Population } \\
\text { attributable } \\
\text { risk }^{\mathrm{a}}\end{array}$ & $\begin{array}{l}\text { Incidence } \\
\text { of } \\
\text { outcome } \\
\text { measure }\end{array}$ & $\begin{array}{l}\text { Incidence } \\
\text { attributable } \\
\text { to risk } \\
\text { factor }^{\mathrm{a}}\end{array}$ & $\begin{array}{l}\text { Annual } \\
\text { number of } \\
\text { outcome } \\
\text { events } \\
\text { avoided by } \\
\text { achieving } \\
\text { target }^{\mathrm{a}}\end{array}$ \\
\hline $\begin{array}{l}\text { Insufficient } \\
\text { physical } \\
\text { activity }\end{array}$ & $\begin{array}{l}\text { Colorectal } \\
\text { cancer }\end{array}$ & $15 \%$ & $44 \%^{7}$ & $\begin{array}{c}1.14 \\
\text { (relative to adequate } \\
\text { physical activity) }\end{array}$ & $5.3 \%$ & $4744^{45}$ & 249 & 37 cases \\
\hline $\begin{array}{l}\text { Insufficient } \\
\text { fruit } \\
\text { consumption }\end{array}$ & $\begin{array}{l}\text { Coronary } \\
\text { heart } \\
\text { disease }\end{array}$ & $25 \%$ & $47 \%^{7}$ & $\begin{array}{l}1.15 \\
\text { (relative to sufficient } \\
\text { fruit consumption) }\end{array}$ & $16.1 \%$ & $24406^{47}$ & 1479 & 422 cases \\
\hline $\begin{array}{l}\text { Insufficient } \\
\text { vegetable } \\
\text { consumption }\end{array}$ & $\begin{array}{l}\text { Coronary } \\
\text { heart } \\
\text { disease }\end{array}$ & $10 \%$ & $90 \%^{7}$ & $\begin{array}{c}1.19 \\
\text { (relative to } \\
\text { sufficient vegetable } \\
\text { consumption) }{ }^{46}\end{array}$ & $14.4 \%$ & $24406^{47}$ & 3515 & 351 cases \\
\hline $\begin{array}{l}\text { Sugar- } \\
\text { sweetened } \\
\text { beverage } \\
\text { consumption }\end{array}$ & $\begin{array}{l}\text { Type } 2 \\
\text { diabetes }\end{array}$ & $25 \%$ & $29 \%^{8}$ & $\begin{array}{l}1.20 \\
\text { (relative to no } \\
\text { consumption) }{ }^{48}\end{array}$ & $4.9 \%$ & $42080^{49}$ & 2041 & 510 cases \\
\hline $\begin{array}{l}\text { Sedentary } \\
\text { behaviour } \\
\text { (sitting for } \\
\geq 10 \text { hours per } \\
\text { day) }\end{array}$ & $\begin{array}{l}\text { All-cause } \\
\text { mortality }\end{array}$ & $25 \%$ & $12 \%^{9}$ & $\begin{array}{c}\text { RR of all-cause } \\
\text { mortality } \\
1.34 \\
\text { (relative to sitting } \\
<7 \text { hours per day, } \\
\text { adjusted for physical } \\
\text { activity) }{ }^{50}\end{array}$ & $3 \%$ & $\begin{array}{l}\text { NSW } \\
\text { incidence } \\
\text { of all- } \\
\text { cause } \\
\text { deaths } \\
\text { (2012): } \\
49314\end{array}$ & 1464 & 366 deaths \\
\hline Overweight & $\begin{array}{l}\text { Type } 2 \\
\text { diabetes }\end{array}$ & $5 \%$ & $\begin{array}{c}\text { Men: } \\
39 \% \\
\text { Women: } \\
25 \% 7\end{array}$ & $\begin{array}{c}\text { Men: } 2.40 \\
\text { Women: } 3.92 \\
\text { (relative to healthy } \\
\text { weight) }\end{array}$ & $\begin{array}{l}\text { Men: } \\
22.5 \% \\
\text { Women: } \\
18.7 \%\end{array}$ & $\begin{array}{l}\text { Men: } \\
23671 \\
\text { Women: } \\
21368^{49}\end{array}$ & $\begin{array}{l}\text { Men: } \\
5316 \\
\text { Women: } \\
3995\end{array}$ & $\begin{array}{l}\text { Men: } \\
266 \text { cases } \\
\text { Women: } \\
200 \text { cases }\end{array}$ \\
\hline Obesity & $\begin{array}{l}\text { Type } 2 \\
\text { diabetes }\end{array}$ & $5 \%$ & $\begin{array}{c}\text { Men: } \\
18 \% \\
\text { Women: } \\
\text { 19\%7 }\end{array}$ & $\begin{array}{c}\text { Men: } 6.74 \\
\text { Women: } 12.41 \\
\text { (relative to healthy } \\
\text { weight) }\end{array}$ & $\begin{array}{c}\text { Men: } \\
\text { 15.7\% } \\
\text { Women: } \\
17.4 \%\end{array}$ & $\begin{array}{l}\text { Men: } \\
23671 \\
\text { Women: } \\
21368^{49}\end{array}$ & $\begin{array}{c}\text { Men: } \\
3709 \\
\text { Women: } \\
3713\end{array}$ & $\begin{array}{l}\text { Men: } \\
185 \text { cases } \\
\text { Women: } \\
186 \text { cases }\end{array}$ \\
\hline
\end{tabular}

\footnotetext{
a Because this modelling used $P_{e}$ (prevalence of exposure from population surveys), not $P_{d}$ (prevalence of exposure in those with the outcome of interest), these are likely to be underestimates.
} 


\section{Discussion}

The concept of a comprehensive approach to obesity prevention and control is not new in Australia ${ }^{39}$ or internationally. ${ }^{1}$ However, efforts to move from planning to implementation of these comprehensive approaches is a recent phenomenon, now emerging in several countries. ${ }^{2}$ These approaches are encouraged by the Global Action Plan (GAP) for the prevention and control of noncommunicable diseases 2013-2020, endorsed by the 66th World Health Assembly (http://apps.who. int/gb/ebwha/pdf_files/WHA66/A66_R10-en.pdf). The GAP includes nine voluntary global targets, including a $25 \%$ relative reduction in premature mortality from cardiovascular diseases, cancer, diabetes or chronic respiratory diseases; and a halt in the rise in diabetes and obesity. The obesity target in GAP is less ambitious than the targets stipulated in the HEAL Strategy (see Box 1). A recent global status report from the World Health Organization states that "obesity and diabetes can be prevented through multisectoral action that simultaneously addresses different sectors that contribute to the production, distribution and marketing of food, while concurrently shaping an environment that facilitates and promotes adequate levels of physical activity"; but the report also concedes that "research is urgently needed to evaluate the effectiveness of interventions to prevent and control obesity" (executive summary, page xiv). ${ }^{1}$

Our study of the NSW HEAL Strategy 2013-2018 showcases the range of health outcomes that could be influenced by intersectoral strategies. Note that, as a result of the complex relationships between risk factors/ conditions and health outcomes, the estimated number of avoided events shown in Table 1 cannot be combined to give total avoided events. Monitoring of these targets will confirm whether comprehensive sector-wide strategies represent a logical and evidence-informed approach to addressing the obesity epidemic. A key challenge is the adequacy and sustainability of strategy implementation. Process evaluation of the extent to which full implementation of proven multisectoral strategies is achieved is therefore a central component of evaluating the HEAL Strategy.

Although we acknowledge its importance, assessing the costs and benefits of comprehensive strategy implementation was beyond this study's scope. Outputs from studies such as this (and, in the longer term, the accumulated data on intervention effectiveness) can inform economic modelling of the costs and benefits of the strategy, examples of which have been published. ${ }^{40,41}$ The explicit evidence of the social and health benefits that are likely to be achieved, as determined in the present study, helps strengthen the case for comprehensive, multisectoral action with respect to healthy eating and active living.

\section{Limitations}

This Australian case study is based on the Evidence Check rapid review methodology with additional selective epidemiological modelling. Our grey literature search for overweight and obesity was limited to articles published in the past 2 years. We also did not use some common systematic review techniques, such as searching the bibliographies of included papers for additional relevant references, because of time constraints. This means that we may have missed some relevant papers. In addition, some health behaviours we explored (as represented in the HEAL Strategy objectives) are less well defined than others in the literature. For example, energy-dense, nutrient-poor foods are described in various ways in the literature, making identification of relevant search terms more challenging. In addition, most of the literature does not centre on food groups as such, but focuses on socalled 'negative' nutrients such as salt, saturated fat, and added or total sugars.

In their methodological critique, Flegal and colleagues $^{42}$ have noted the importance of considering whether the exposure and outcome were defined similarly for PAR and for the relative risks, whether the relative risks were suitable for the population at hand, and whether PAR was calculated using correct methods. Every effort was made to address these considerations in our study within the limitations of the available data. Studies for some of the targets and objective behaviours (exposure variables) did not always clearly define the exposure variable, or failed to delineate between associated behaviours sufficiently (e.g. between physical activity and sedentary behaviours). In some cases, they did not fully account for residual confounding.

Many of the meta-analyses used indicated that the outcome of interest was measured in a variety of ways. Nevertheless, large numbers of meta-analyses involving large numbers of studies and participants indicate considerably increased relative risk across a wide range of morbidities and mortality.

The evidence base for children and adolescents was sparse compared with that for adults, partly because many of the health effects involved are longer term and require study designs to accommodate this. Educational outcomes studies in relation to behavioural changes were limited and represent another area where more extensive research would be valuable.

We used a limited number of databases because of the expansive nature of the literature on obesity and risk factor behaviours; some nonhealth outcomes (e.g. educational outcomes, productivity) may be more extensively described within nonhealth databases that were not accessed in this review. However, the possibility that our research team may have missed some additional potential benefits as a result of these limitations means that the measures of association identified in the review are conservative and may underestimate the cumulative effect of intersectoral action. 
These case studies are confined to a few chosen areas, and we have not attempted to describe all the potential benefits that may accrue within the broad scope of the HEAL Strategy. However, these case studies were chosen for their high relative burden of disease in Australia ${ }^{6}$, which, given the comparatively similar chronic disease profiles in developed nations around the world ${ }^{43}$, should mean that our results are relevant to other settings. For our epidemiological models, the prevalence estimates for coronary heart disease and type 2 diabetes are the best available but are subject to a degree of uncertainty. The targeted changes for fruit and vegetable consumption, sugar-sweetened beverage consumption, and sitting time are ambitious, although we believe they are feasible over the longer term. Nonetheless, achieving sustained behaviour change in populations is challenging, and the avoided morbidity and mortality calculated for these objectives should be viewed with caution.

\section{Conclusion}

Obesity prevalence may be reduced through multisectoral action in food production, distribution and marketing, while concurrently shaping an environment that facilitates and promotes sufficient physical activity. A review of evidence and our epidemiological modelling suggest that successful implementation of comprehensive sector-wide strategies targeting overweight and obesity could prevent a large number of chronic disease cases and deaths. Some notable outcomes beyond the traditional health sector boundaries (disability payments, absenteeism, worker productivity, workplace injuries, insurance claims) were also identified in our review, but more extensive confirmatory research is required. Sector-wide health, social and economic benefits from successful implementation of these comprehensive strategies are likely to be substantial if specified targets are achieved. This paper provides an example of modelling that can provide estimates of potential lives saved and diseases prevented through strategy implementation; these estimates are illustrative rather than definitive, but nonetheless compelling. Evaluation of the extent to which full implementation of proven multisectoral strategies is achieved and their potential benefits are realised is now a global priority.

\section{Acknowledgements}

This research was supported by the Australian Prevention Partnership Centre through the National Health and Medical Research Council (NHMRC) Partnership Centre grant scheme (grant ID: GNT9100001) with the Australian Government Department of Health, the NSW Ministry of Health, ACT Health, HCF and the HCF Research Foundation.

\section{Competing interests}

None declared

\section{Author contributions}

$\mathrm{AB}, \mathrm{BB}, \mathrm{PH}$ and JM conceptualised the study. AStG conducted the searches (except for overweight and obesity, for which the searching and screening were conducted by $\mathrm{DH}$ ) and some of the screening; JK undertook the remainder of the screening and most of the tabulation. Tabulation of physical activity and sedentary behaviours was conducted by ZP. Epidemiological models were prepared by JK. Studies, tabulation and epidemiological models were checked independently by $\mathrm{AB}$ and $\mathrm{BB}$. All authors contributed to manuscript development.

\section{References}

1. World Health Organization. Global status report on noncommunicable diseases 2014. Geneva: World Health Organization; 2014 [cited 2015 Aug 25]. Available from: www.who.int/nmh/publications/ncd-status-report-2014/en/

2. OECD Directorate for Employment, Labour and Social Affairs. Obesity update: June 2014. Paris: Organisation for Economic Cooperation and Development; 2014 [cited 2015 Aug 25]. Available from: www.oecd.org/health/ Obesity-Update-2014.pdf

3. Guh D, Zhang W, Bansback N, Amarsi Z, Birmingham CL, Anis $A$. The incidence of co-morbidities related to obesity and overweight: a systematic review and meta-analysis. BMC Public Health. 2009;9(1):88.

4. Dee A, Kearns K, O'Neill C, Sharp L, Staines A, O'Dwyer $\mathrm{V}$, et al. The direct and indirect costs of both overweight and obesity: a systematic review. BMC Res Notes. 2014;7:242.

5. Roberto CA, Swinburn B, Hawkes C, Huang TT, Costa SA, Ashe M, et al. Patchy progress on obesity prevention: emerging examples, entrenched barriers, and new thinking. Lancet. 2015;385(9985):2400-9.

6. Begg S, Vos T, Barker B, Stevenson C, Stanley L, Lopez A. The burden of disease and injury in Australia 2003. Canberra: Australian Institute of Health and Welfare; 2007 [cited 2015 Aug 25]. Available from: www. aihw.gov.au/publication-detail/?id=6442467990

7. Centre for Epidemiology and Evidence. HealthStats NSW. Sydney: NSW Ministry of Health; 2014 [cited 2015 Aug 25]. Available from: www.healthstats.nsw.gov. $\mathrm{au}$

8. Australian Bureau of Statistics. Australian health survey: nutrition first results - food and nutrients, 2011-12. Canberra: Commonwealth of Australia: 2014 [cited 2015 Aug 25]. Available from: www.abs.gov.au/ausstats/ abs@.nsf/Lookup/4364.0.55.007main+features12011-12 
9. Bauman A, Ainsworth BE, Sallis JF, Hagstromer M, Craig CL, Bull FC, et al. The descriptive epidemiology of sitting. A 20-country comparison using the International Physical Activity Questionnaire (IPAQ). Am J Prev Med. 2011;41(2):228-35.

10. Lee IM, Shiroma EJ, Lobelo F, Puska P, Blair SN, Katzmarzyk PT. Effect of physical inactivity on major non-communicable diseases worldwide: an analysis of burden of disease and life expectancy. Lancet. 2012;380(9838):219-29.

11. Neuhaus M, Eakin EG, Straker L, Owen N, Dunstan DW, Reid N, et al. Reducing occupational sedentary time: a systematic review and meta-analysis of evidence on activity-permissive workstations. Obes Rev. 2014;15(10):822-38.

12. Avery A, Bostock L, McCullough F. A systematic review investigating interventions that can help reduce consumption of sugar-sweetened beverages in children leading to changes in body fatness. J Hum Nutr Diet. 2015;28(Suppl 1):52-64.

13. Flegal KM, Kit BK, Orpana H, Graubard BI. Association of all-cause mortality with overweight and obesity using standard body mass index categories: a systematic review and meta-analysis. JAMA. 2013;309(1):71-82.

14. Bell JA, Kivimaki M, Hamer M. Metabolically healthy obesity and risk of incident type 2 diabetes: a metaanalysis of prospective cohort studies. Obes Rev. 2014; 15(6):504-15.

15. Zhou ZY, Liu YK, Chen HL, Liu F. Body mass index and knee osteoarthritis risk: a dose-response meta-analysis. Obesity (Silver Spring). 2014;22(10):2180-5.

16. Zhang Y, Liu H, Yang S, Zhang J, Qian L, Chen X. Overweight, obesity and endometrial cancer risk: results from a systematic review and meta-analysis. Int J Biol Markers. 2014;29(1):e21-9.

17. Wu S, Liu J, Wang X, Li M, Gan Y, Tang Y. Association of obesity and overweight with overall survival in colorectal cancer patients: a meta-analysis of 29 studies. Cancer Causes Control. 2014;25(11):1489-502.

18. Wang F, Xu Y. Body mass index and risk of renal cell cancer: a dose-response meta-analysis of published cohort studies. Int J Cancer. 2014;135(7):1673-86.

19. Druesne-Pecollo N, Touvier M, Barrandon E, Chan DS, Norat T, Zelek L, et al. Excess body weight and second primary cancer risk after breast cancer: a systematic review and meta-analysis of prospective studies. Breast Cancer Res Treat. 2012;135(3):647-54.

20. Lin XJ, Wang CP, Liu XD, Yan KK, Li S, Bao HH, et al. Body mass index and risk of gastric cancer: a metaanalysis. Jpn J Clin Oncol. 2014;44(9):783-91.

21. Qin Q, Xu X, Wang X, Zheng XY. Obesity and risk of bladder cancer: a meta-analysis of cohort studies. Asian Pac J Cancer Prev. 2013;14(5):3117-21.
22. Golabek T, Bukowczan J, Chlosta P, Powroznik J, Dobruch J, Borowka A. Obesity and prostate cancer incidence and mortality: a systematic review of prospective cohort studies. Urol Int. 2014;92(1):7-14.

23. Zhao ZG, Guo XG, Ba CX, Wang W, Yang YY, Wang J, et al. Overweight, obesity and thyroid cancer risk: a meta-analysis of cohort studies. J Int Med Res. 2012;40(6):2041-50.

24. Shiri R, Lallukka T, Karppinen J, Viikari-Juntura E. Obesity as a risk factor for sciatica: a meta-analysis. Am J Epidemiol. 2014;179(8):929-37.

25. Park M, Song da $Y$, Je $Y$, Lee JE. Body mass index and biliary tract disease: a systematic review and meta-analysis of prospective studies. Prev Med. 2014;65:13-22.

26. Pan CW, Lin Y. Overweight, obesity, and agerelated cataract: a meta-analysis. Optom Vis Sci. 2014;91(5):478-83.

27. Meehan S, Beck CR, Mair-Jenkins J, Leonardi-Bee J, Puleston R. Maternal obesity and infant mortality: a metaanalysis. Pediatrics. 2014;133(5):863-71.

28. Withrow D, Alter DA. The economic burden of obesity worldwide: a systematic review of the direct costs of obesity. Obes Rev. 2011;12(2):131-41.

29. Van Nuys K, Globe D, Ng-Mak D, Cheung H, Sullivan J, Goldman D. The association between employee obesity and employer costs: evidence from a panel of U.S. employers. Am J Health Promot. 2014;28(5):277-85.

30. Kleinman N, Abouzaid S, Andersen L, Wang Z, Powers A. Cohort analysis assessing medical and nonmedical cost associated with obesity in the workplace. J Occup Environ Med. 2014;56(2):161-70.

31. Robroek SJ, Reeuwijk KG, Hillier FC, Bambra CL, van Rijn RM, Burdorf A. The contribution of overweight, obesity, and lack of physical activity to exit from paid employment: a meta-analysis. Scand J Work Environ Health. 2013;39(3):233-40.

32. Trogdon JG, Finkelstein EA, Hylands T, Dellea PS, KamalBahl SJ. Indirect costs of obesity: a review of the current literature. Obes Rev. 2008;9(5):489-500.

33. Pulgaron ER. Childhood obesity: a review of increased risk for physical and psychological comorbidities. Clin Ther. 2013;35(1):A18-32.

34. van Geel M, Vedder P, Tanilon J. Are overweight and obese youths more often bullied by their peers? A meta-analysis on the relation between weight status and bullying. Int J Obes. 2014;38(10):1263-7.

35. Friedemann C, Heneghan C, Mahtani K, Thompson M, Perera R, Ward AM. Cardiovascular disease risk in healthy children and its association with body mass index: systematic review and meta-analysis. BMJ. 2012;345:e4759. 
36. Hoare E, Skouteris H, Fuller-Tyszkiewicz M, Millar L, Allender S. Associations between obesogenic risk factors and depression among adolescents: a systematic review. Obes Rev. 2014;15(1):40-51.

37. Bechard LJ, Rothpletz-Puglia P, Touger-Decker R, Duggan C, Mehta NM. Influence of obesity on clinical outcomes in hospitalized children: a systematic review. JAMA Pediatr. 2013;167(5):476-82.

38. Ahmed S, Arjmand E, Sidell D. Role of obesity in otitis media in children. Curr Allergy Asthma Rep. 2014;14(11):469.

39. National Health and Medical Research Council. Acting on Australia's weight: a strategic plan for the prevention of overweight and obesity 1996. Canberra: Australian Government; 1996 [cited 2015 Aug 25]. Available from: www.nhmrc.gov.au/guidelines/publications/n21-n22

40. Carter R, Moodie M, Markwick A, Magnus A, Vos T, Swinburn B, Haby MM. Assessing cost-effectiveness in obesity (ACE-obesity): an overview of the ACE approach, economic methods and cost results. BMC Public Health. 2009;9:419.

41. Lehnert T, Sonntag D, Konnopka A, Riedel-Heller S., Konig $\mathrm{HH}$. The long-term cost-effectiveness of obesity prevention interventions: systematic literature review. Obes Rev. 2012;13(6):537-53.

42. Flegal KM, Panagiotou OA, Graubard BI. Estimating population attributable fractions to quantify the health burden of obesity. Ann Epidemiol. 2015;25(3):201-7.

43. World Health Organization. Global status report on noncommunicable diseases 2014; Geneva: World Health Organization; 2014 [cited 2015 Aug 26]. Available from: www.who.int/nmh/publications/ncd-status-report-2014/en/
44. Johnson CM, Wei C, Ensor JE, Smolenski DJ, Amos Cl, Levin B, Berry DA. Meta-analyses of colorectal cancer risk factors. Cancer Causes Control. 2013;24(6):1207-22.

45. Currow D, Thomson W. Cancer in NSW: incidence report 2009. Sydney: Cancer Institute NSW; 2014 [cited 2015 Aug 26]. Available from: www.cancerinstitute.org. au/media/337679/cancer-in-nsw-incidence-report-2009. pdf

46. He FJ, Nowson CA, Lucas M, MacGregor GA. Increased consumption of fruit and vegetables is related to a reduced risk of coronary heart disease: meta-analysis of cohort studies. J Hum Hypertens. 2007;21(9):717-28.

47. Australian Institute of Health and Welfare. Cardiovascular disease, diabetes and chronic kidney disease Australian facts: prevalence and incidence; 2014 [cited 2015 Aug 27]. Available from: www.aihw.gov.au/ WorkArea/DownloadAsset.aspx?id=60129549614

48. Greenwood DC, Threapleton DE, Evans CEL, Cleghorn CL, Nykjaer C, Woodhead C, Burley VJ. Association between sugar-sweetened and artificially sweetened soft drinks and type 2 diabetes: systematic review and dose-response meta-analysis of prospective studies. Br J Nutr. 2014;112(5):725-34.

49. Magliano DJ, Barr ELM, Zimmet PZ, Cameron AJ, Dunstan DW, Colagiuri S, et al. Glucose indices, health behaviors, and incidence of diabetes in Australia: the Australian Diabetes, Obesity and Lifestyle Study. Diabetes Care. 2008;31(2):267-72.

50. Chau JY, Grunseit AC, Chey T, Stamatakis E, Brown WJ, Matthews CE, et al. Daily sitting time and all-cause mortality: a meta-analysis. PLoS ONE. 2013;8(11):e80000

\section{Copyright: (c) (i) (2)}

(C) 2015 Kite et al. This article is licensed under the Creative Commons Attribution-NonCommercial-ShareAlike 4.0 International Licence, which allows others to redistribute, adapt and share this work non-commercially provided they attribute the work and any adapted version of it is distributed under the same Creative Commons licence terms. See: www.creativecommons.org/licenses/by-nc-sa/4.0/ 